\title{
Migrating fish bone in neck
}

\section{Siddharth A. Shroff*, Mohammed Humaam Ansari, Naman Agarwal}

\author{
Department of ENT, Dr. Shankar Rao Chavan Government Medical College, Nanded, Maharashtra, India
}

Received: 13 February 2019

Revised: 22 May 2019

Accepted: 29 May 2019

\author{
*Correspondence: \\ Dr. Siddharth A. Shroff, \\ E-mail: siddharthshroff92@gmail.com
}

Copyright: () the author(s), publisher and licensee Medip Academy. This is an open-access article distributed under the terms of the Creative Commons Attribution Non-Commercial License, which permits unrestricted non-commercial use, distribution, and reproduction in any medium, provided the original work is properly cited.

\begin{abstract}
Foreign body ingestion is very common in Asian population among which most common ingested foreign body is fish bone (FB). It usually presents with foreign body sensation, odynophagia or pricking sensation during deglutition. Usually diagnosis is achieved on basis of lateral radiograph of neck, videolaryngoscopy and oesophagoscopy. Sometimes FB migrates extraluminally and causes deep neck abscess, vascular complications including vascular esophageal fistula, puncture of carotid artery, thromboembolism, thyroid gland retention. Here we report a case where fish bone migrated extraluminally into neck piercing the carotid sheath and jarred between external carotid artery and internal carotid artery. Initial laryngoscopy and oesophagoscopy were both negative. Urgent Surgical exploration was planned due to severe pain and discomfort to patient and $4 \mathrm{~cm}$ fish bone was retrieved. Fish bone ingestion is the most common ingested foreign body encountered in otorhinolaryngology practice. Fish bones are most commonly impacted at base of tongue, palatine tonsil or vallecula. Sometimes fish bone extraluminally and causes various complications. Extraluminal migration of fish bone is very rare and very few cases have been reported and the only case reported from our region.
\end{abstract}

Keywords: Fish bone, Extraluminal, Migration

\section{INTRODUCTION}

Fish bone is the most common ingested foreign body in Asian population. It usually presents with foreign body sensation, odynophagia or pricking sensation during deglutition. Most of the patients seek medical attention and recover well without any unwanted complications by passing down the gastrointestinal tract. ${ }^{1}$ Few of the fish bones are retained in the oesophagus. ${ }^{2}$ Delay detection of fish bone impaction or missing bone is usually due to negative findings of laryngoscopy and also due to low sensitivity of lateral neck radiograph. ${ }^{4}$ In such cases where fish bone has migrated extraluminally would result a negative laryngoscopy and oesophagoscopy. Here we report a rare and only case reported from our region where fish bone migrated extraluminally into neck piercing into carotid sheath and jarred between external carotid artery and internal carotid artery.

\section{CASE REPORT}

A 30 year old male presented to our outpatient department with a progressively worsening sore throat, odynophagia and neck pain of several days. The patient had suffered from these symptoms since 2 days after eating fish. On physical examination, the patient had severe tenderness on right side of the neck and a sharp pointed object located in the subcutaneous tissue of the right side of the neck. He went to a local public health care centre after which he was referred to our centre. After which he underwent laryngoscopy, rigid oeophagoscopy at our centre but no foreign body was found. A lateral neck X-ray revealed a radio-opaque mass at the level of C6-C7 cervical vertebral body. As patient was in severe discomfort due to pain on right side of neck we arranged for an urgent surgical exploration of neck under general anesthesia for extraction of foreign body. A 
5-cm horizontal incision was made in right neck and tip of fish bone became apparent after dissecting the subcutaneous tissue. Further dissection was done till base of the fish bone which was embedded between RT ECA and ICA without piercing the common carotid artery and fish bone was extracted and was shown to be $4 \mathrm{~cm}$ long with a sharp pointed tip. The wound was closed in layers and romovac drain no 14 . Kept in wound and was removed subsequently on post-operative day 3 . The patient was kept nil by mouth for 48 hours. The patient returned to normal diet and was discharged on day 6 of hospitalization.

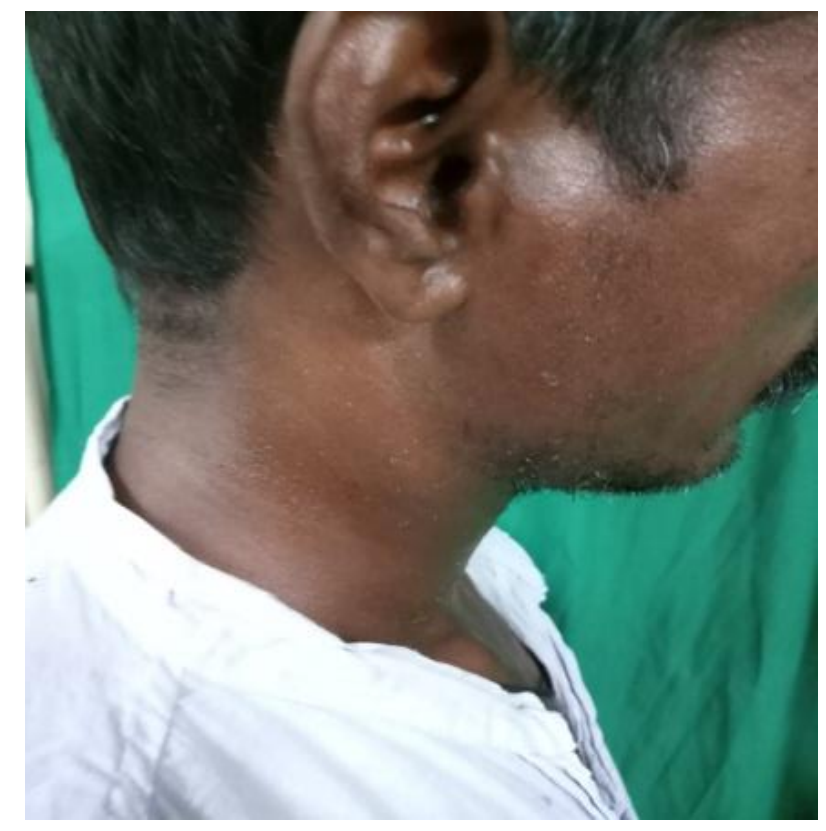

Figure 1: Pointed sharp object visualized at right side of neck.

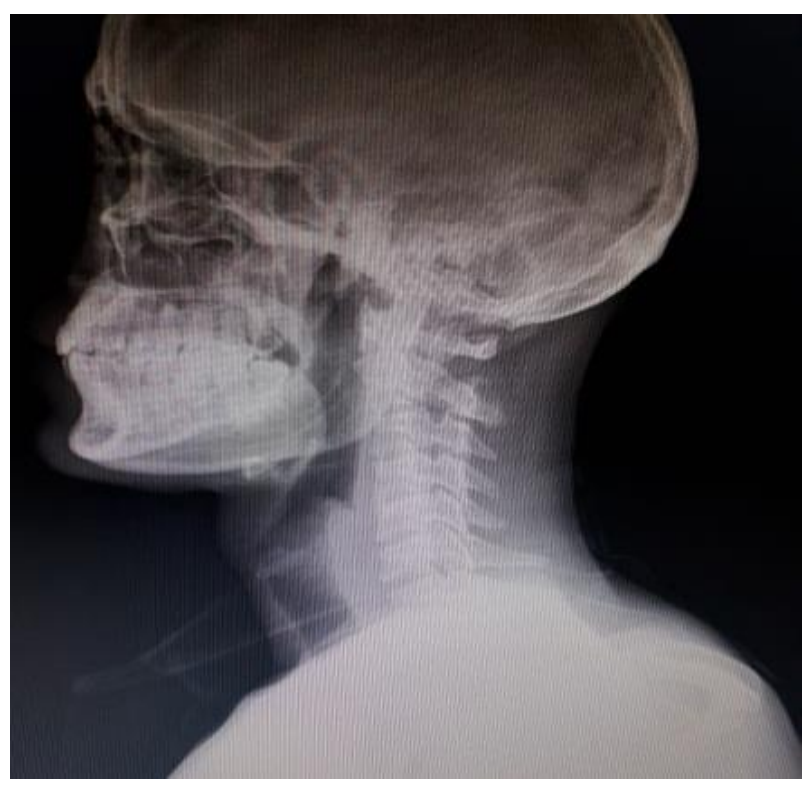

Figure 2: X-ray neck lateral view suggestive of a foreign body at the level of C6-C7.



Figure 3: Intra-operative still suggestive of fish bone.

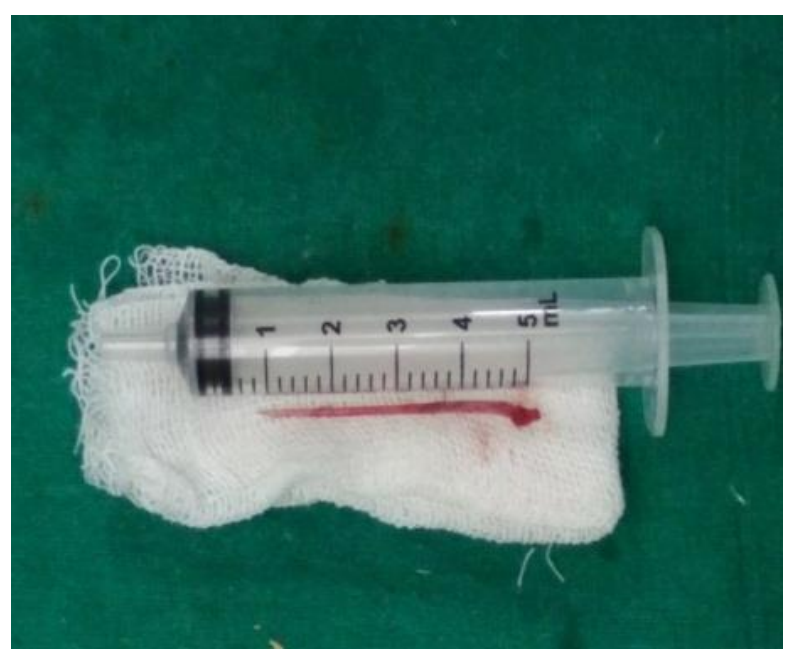

Figure 4: The $4 \mathrm{~cm}$ long sharp pointed fish bone.

\section{DISCUSSION}

Fish bone ingestion is the most common ingested foreign body encountered in otorhinolaryngology practice. Most of these patients presents within $24 \mathrm{hrs}$. Fish bones are most commonly impacted at base of tongue, palatine tonsil or vallecula which can be easily removed in OPD setting without any significant complications. Other sites like pyriform fossa, the epiglottis, the esophagus incidence being $5 \%$ can also be involved. ${ }^{3}$ A detailed examination and simple radiograph of neck are useful for diagnosis. Lue et al reported a sensitivity and specificity of plain radiography as $39 \%$ and $72 \%$ respectively. ${ }^{4}$ Very rarely, an ingested FB can also penetrate through GI tract and become ingested in soft tissues of the neck. In the presence of positive neck radiography, negative laryngoscopy and oesophagoscopy suspicion goes towards the migrating fish bone. Sometimes FB migrates extraluminally and causes deep neck abscess, vascular complications including vascular esophageal fistula, puncture of carotid artery, thromboembolism, thyroid 
gland retention. ${ }^{5}$ Very rarely inflammatory pseudotumour of liver when fish bone tracked down to gastrointestinal tract. ${ }^{6}$ A foreign body under the forces of gravity and pressure in the surrounding tissues tends to move towards planes of least resistance, and like pus, will find its way out. The fish bone migration is attributed by several factors like orientation, pointed shape of fish bone, contraction of cricopharyngeus muscle during swallowing. ${ }^{7,8}$ Chee et al concluded that horizontal orientation of the fish bone are more likely to migrate extraluminally. ${ }^{8}$ CT scan can be considered best diagnostic tool for better detection of FB type, size, orientation, location and its relationship to other vital structures in the neck.

\section{CONCLUSION}

Extraluminal migration of fish bone is very rare and very few cases have been reported and the only case reported from our region.

Funding: No funding sources

Conflict of interest: None declared

Ethical approval: Not required

\section{REFERENCES}

1. Ngan JH, Fok PJ, Lai EC, Branicki FJ, Wong J. A prospective study on fish bone ingestion. Experience of 358 patients. Ann Surg. 1989;211(4):459-62.
2. Scher RL, Tegtmeyer CJ, McLean WC. Vascular injury following foreign body perforation of the esophagus: review of the literature and report of a case. Ann Otol Rhinol Laryngol. 1990;99(9 Pt 1): 698-702.

3. Yang SW, Chen TM, Chen TA. Migrating fish bone complicating a deep neck abscess. Chang Gung Med J. 2005;28:872-5.

4. Lue AJ, Fang WD, Manolidis S. Use of plain radiography and computed tomography to identify fish bone foreign bodies. Otolaryngol Head Neck Surg. 2000;123:435-8.

5. Lin $\mathrm{YH}, \mathrm{Ho} \mathrm{HC}$, Hsiao SH. An ingested fishbone migrating to the thyroid gland: a case report. Tzu Chi Med J. 2006;18:438-41.

6. Srinivasan UP, Duraisamy AB, Ilango S, Rathinasamy A, Chandramohan SM. Inflammatory pseudotumor of liver secondary to migrated fishbone: a rare cause with an unusual presentation. Ann Gastroenterol. 2013;26:84-6.

7. Sabari NH, Jayakumar RM, Manju EI, Meera G, Greeshma KM. Fishing for fishbone in neck. Glob J Oto. 2017;4(2):555633.

8. Chee LW, Sethi DS. Diagnostic and therapeutic approach to migrating foreign bodies. Ann Otol Rhinol Laryngol. 1999;108:177-80.

Cite this article as: Shroff SA, Ansari MH, Agarwal N. Migrating fish bone in neck Int J Otorhinolaryngol Head Neck Surg 2019;5:1104-6. 